\title{
cIMP: Synthesis, effector activation, inactivation and occurrence in biological systems
}

\author{
Roland Seifert ${ }^{1 *}$, Christina Hartwig ${ }^{1}$, Sabine Wolter ${ }^{1}$, Erich Schneider ${ }^{1}$, Heike Bähre ${ }^{1,2}$, Volkhard Kaever ${ }^{1,2}$ \\ From 7th International Conference on cGMP Generators, Effectors and Therapeutic Implications \\ Trier, Germany. 19-21 June 2015
}

\begin{abstract}
Background
The soluble nitric oxide (NO)-stimulated guanylyl cyclase (sGC) uses GTP as a substrate to synthesize the secondary messenger cGMP [1]. However, sGC is not so stringent in terms of substrate-specificity and can also use ATP to produce yet another secondary messenger, cAMP [1]. Both cAMP and cGMP induce vasodilation. Recently, it has been proposed that under conditions of hypoxia, sGC predominantly produces cIMP to induce vasoconstriction [2]. Chemically, cGMP and cIMP are very closely related to each other, i.e. the only chemical difference between the two cyclic nucleotides is the missing amino group at the 2'-position of the purine ring (Fig. 1). How can such a small chemical difference between two molecules lead to opposite biological effects? To answer this question, we studied cIMP synthesis, effector activation, inactivation and biological occurrence.
\end{abstract}

\section{Methods}

We determined cGMP and cIMP concentrations with a highly sensitive and specific HPLC-MS/MS method that was previously described in detail $[1,3]$. We analysed purified $s G C \alpha_{1} \beta_{1}[1]$, recombinant particulate GC-A (pGC-A) expressed in HEK293 cell membranes or intact HEK293 cells [3], recombinant cAMP- and cGMPdependent protein kinases (PKA and PKG, respectively) [4], and various recombinant phosphodiesterases (PDEs) $[5,6]$. We also determined cIMP concentrations in various biological systems [7].

\section{Results}

Purified sGC and recombinant pGC-A expressed in HEK293 cells were very effective at producing cIMP. $K_{m}$

\footnotetext{
* Correspondence: seifert.roland@mh-hannover.de

'Institute of Pharmacology, Hannover Medical School, Hannover, Germany
} Full list of author information is available at the end of the article and $V_{\max }$ values depended on the presence of $\mathrm{Mg}^{2+}$ or $\mathrm{Mn}^{2+}$ as divalent cation. Under certain conditions, ITP clearly surpassed GTP in terms of $V_{\max }$. The bacterial toxins CyaA from Bordetella pertussis and edema factor from Bacillus anthracis also produced cIMP, but efficiency was very low. However, in intact cells we did not obtain any evidence for cIMP production by sGC, pGCA or bacterial toxins, including ExoY from Pseudomonas aeruginosa. Cyclic nucleotides activated PKA isoforms RI and RII in the potency order cAMP > cIMP > cGMP, and PKGI was activated in the potency order cGMP > cIMP cAMP. At PKA, all cyclic nucleotides were full activators, whereas at PKGI , the order of efficacy was cGMP > cIMP > cAMP. With the exception of PDEs 4B and 8A, all other PDEs studied (PDE1A3, 1B, $2 \mathrm{~A}, 3 \mathrm{~A}, 3 \mathrm{~B}, 5 \mathrm{~A}, 6 \mathrm{AB}, 7 \mathrm{~A} 1,9 \mathrm{~A}$ and $11 \mathrm{~A} 1$ ), hydrolysed cIMP very effectively. In 23 cultured mammalian cell lines from mesenchymal, epithelial and neuronal origin (6 different species), various primary human and rat cells, mouse heart and model organisms including Caenorhabditis elegans, Drosophila melanogaster, Saccharomyces cerevisiae, Escherichia coli and Arabidopsis thaliana we did not identify cIMP. In contrast, all systems studied contained cAMP, and several systems additionally contained cGMP.

\section{Conclusions}

sGC and pGC-A synthesize cIMP in vitro. However, in intact cells, there is no evidence for the occurrence of cIMP and sGC- and pGC-A-mediated cIMP formation. To this end, we have not yet explicitly studied hypoxic conditions. cIMP is a low-potency activator of PKA and PKG. For most PDEs, cIMP is an excellent substrate. This could result in rapid elimination of endogenous cIMP in cells. Our attempts to identify cIMP in organs have been unsuccessful so far. Collectively, presently, we do not have sufficient experimental evidence to support 
<smiles>CC(C)(C)OP(=O)(O)OC1C2OC(C1O)N1C=Nc3c(nc(N)[nH]c3=O)N1O2</smiles>

the notion that cIMP serves as second messenger with functions opposite to those of cAMP and cGMP. Extensive studies with biological models under hypoxic conditions are required. In addition, specific cIMP-binding proteins have to be identified. It cannot be excluded that under very specific experimental conditions, cIMP does have a signalling role. One should also keep in mind that cyclic nucleotides can exert biological effects extracellularly via receptors and ion channels.

\section{Authors' details}

1 Institute of Pharmacology, Hannover Medical School, Hannover, Germany.

${ }^{2}$ Core Unit Metabolomics, Hannover Medical School, Hannover, Germany.

Published: 2 September 2015

\section{References}

1. Beste KY, Burhenne H, Kaever V, Stasch JP, Seifert R: Nucleotidyl cyclase activity of soluble guanylyl cyclase $\alpha 1 \beta 1$. Biochemistry 2012, 51:194-204.

2. Chen Z, Zhan X, Ying L, Dou D, Li Y, Bai Y, Liu J, Liu L, Feng H, Yu X, Leung SW, Vanhoutte PM, Gao Y: cIMP synthesized by SGC as a mediator of hypoxic contraction of coronary arteries. Am J Physiol Heart Circ Physiol 2014, 307(3):H328-H336.

3. Beste KY, Spangler CM, Burhenne H, Koch KW, Tang WJ, Kaever V, Seifert R: Nucleotidyl cyclase activity of particulate guanylyl cyclase A: comparison with particulate guanylyl cyclases $\mathrm{E}$ and $\mathrm{F}$, soluble guanylyl cyclase and bacterial adenylyl cyclases CyA and edema factor. PLoS One 2013, 8(7): e70223.

4. Wolter S, Golombek M, Seifert R: Differential activation of CAMP- and cGMP-dependent protein kinases by cyclic purine and pyrimidine nucleotides. Biochem Biophys Res Commun 2011, 415(4):563-566.

5. Reinecke D, Burhenne H, Sandner P, Kaever V, Seifert R: Human cyclic nucleotide phosphodiesterases possess a much broader substratespecificity than previously appreciated. FEBS Lett 2011, 585(20):3259-3262.

6. Monzel M, Kuhn M, Bähre H, Seifert R, Schneider EH: PDE7A1 hydrolyzes cCMP. FEBS Lett 2014, 588(18):3469-3474.

7. Hartwig C, Bähre H, Wolter S, Beckert U, Kaever V, Seifert R: CAMP, cGMP, CCMP and CUMP concentrations across the tree of life: High cCMP and cUMP levels in astrocytes. Neurosci Lett 2014, 579:183-187.

doi:10.1186/2050-6511-16-S1-A85

Cite this article as: Seifert et al:: cIMP: Synthesis, effector activation, inactivation and occurrence in biological systems. BMC Pharmacology and Toxicology 2015 16(Suppl 1):A85.

\section{Submit your next manuscript to BioMed Central} and take full advantage of:

- Convenient online submission

- Thorough peer review

- No space constraints or color figure charges

- Immediate publication on acceptance

- Inclusion in PubMed, CAS, Scopus and Google Scholar

- Research which is freely available for redistribution 